\title{
Immunity to $\alpha$-Gal: The Opportunity for Malaria and Tuberculosis Control
}

\begin{abstract}
Alejandro Cabezas-Cruz ${ }^{1,2,3 *}$ and José de la Fuente ${ }^{4,5 *}$
${ }^{1}$ UMR BIPAR, INRA, ANSES, Ecole Nationale Vétérinaire d'Alfort, Université Paris-Est, Paris, France, ${ }^{2}$ Faculty of Science, University of South Bohemia, České Budějovice, Czechia, ${ }^{3}$ Institute of Parasitology, Biology Center, Czech Academy of Sciences, České Budějovice, Czechia, ${ }^{4}$ SaBio, Instituto de Investigación en Recursos Cinegéticos IREC (CSIC-UCLMJCCM), Ciudad Real, Spain, ${ }^{5}$ Department of Veterinary Pathobiology, Center for Veterinary Health Sciences, Oklahoma State University, Stillwater, OK, United States
\end{abstract}

Keywords: $\alpha$-Gal, blood groups, infectious diseases, probiotic, vaccine

\section{INFECTIOUS DISEASES, A CHALLENGE TO MODERN MEDICINE}

Among all infectious diseases, malaria and tuberculosis constitute leading causes of morbidity and mortality of human populations in developed and undeveloped countries $(1,2)$. In 2015, the WHO reported that 10.4 million people had tuberculosis and 1.8 million of them died from the disease (1). Despite a reduction of malaria cases between 2000 and 2015 (3), the WHO reported 212 million cases and 429,000 deaths due to this disease in 2015 alone (2). Drug resistance to first-line antimalarial drugs (e.g., chloroquine, sulfadoxine-pyrimethamine, and artemisinin) is a major constrain of malaria control Sub-Saharan Africa (4). Likewise, multidrug-resistant tuberculosis is a growing problem worldwide (5). Thus, the control of these diseases is among the most challenging tasks of public health worldwide. Drug overuse and misuse are recognized as the main drivers of drug resistance in parasites and pathogenic bacteria $(4,6)$. The identification of genetic factors affecting the susceptibility to these infectious diseases is essential toward reducing drug overuse and inappropriate treatment regimes. In this opinion, we propose that blood groups, a major driver of anti- $\alpha$-Gal immunity and malaria and tuberculosis incidence (7), can be used to tailor antimalaria and anti-tuberculosis vaccination. Blood group $\mathrm{A}$ and $\mathrm{O}$ individuals, that can potentially develop strong anti- $\alpha$-Gal immunity (8), could be immunized with probiotic-based vaccines to enhance the natural levels of anti- $\alpha$-Gal antibodies. This immunity could lead to protection against these diseases which in turn would reduce the use of anti-malaria and anti-tuberculosis drugs.

\section{BLOOD GROUPS, INFECTIOUS DISEASES, AND ANTI- $\alpha-G A L$ IMMUNITY}

The $\mathrm{ABO}$ histo-blood groups consist of two antigens ( $\mathrm{A}$ and $\mathrm{B})$, and four blood types $(\mathrm{A}, \mathrm{B}, \mathrm{AB}$, and $\mathrm{O}$ ) of which blood types $\mathrm{A}, \mathrm{B}$, and $\mathrm{O}$ are the most frequent among human populations, being the $\mathrm{O}$ type the most common (9). The blood type $\mathrm{O}$ results from the homozygous inheritance of two null $\mathrm{ABO}$ alleles and individuals in this group express the antigen $\mathrm{H}$, the precursor of blood types $\mathrm{A}$ and $\mathrm{B}$ (Figure 1). The ABH antigens are carbohydrates attached to glycosphingolipids and glycoproteins. In general, humans have antibodies against missing A or B antigens (9). Therefore, individuals with blood type A have antibodies against antigen B, but not against self-antigen A (9). Individuals with blood type $\mathrm{O}$ have antibodies against both $\mathrm{A}$ and $\mathrm{B}$ antigens (9). The $\mathrm{ABO}$ blood type correlates with the susceptibility and severity of malaria and tuberculosis (9-11). However, so far, most of the mechanisms relating $\mathrm{ABO}$ blood types to infectious diseases are based on host cell-pathogen interactions $(12,13)$. For example, blood type O protects against severe malaria caused by Plasmodium falciparum through the mechanism of reduced rosetting (i.e., spontaneous binding of infected erythrocytes to uninfected erythrocytes) (12). By contrast, blood type A 


\section{$A B O$ antigens}

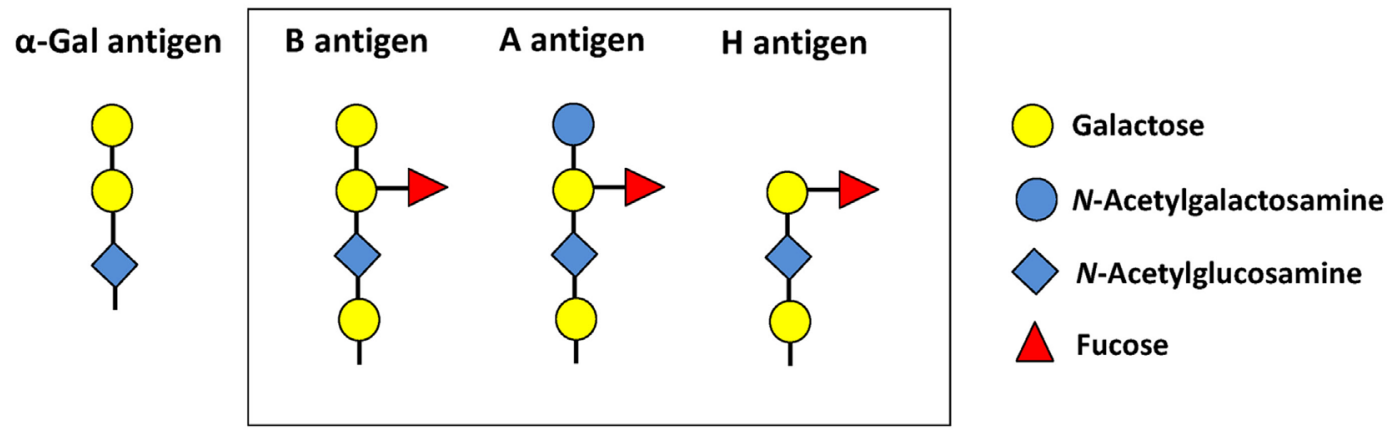

FIGURE 1 | Glycan structure of blood group antigens and $\alpha$-Gal. Blood type B, A, and O individuals express the B, A, and $\mathrm{H}$ antigens, respectively. Adapted from Ref. $(8,9)$.

individuals are more susceptible to severe malaria because the $P$. falciparum-encoded repetitive interspersed families of polypeptides, expressed on the surface of infected red blood cells, binds more efficiently blood group A and increases the rosetting (13). Recent findings, however, showed that gut microbiota induces a protective immune response against malaria transmission by mosquitoes (14). This mechanism was associated to the antigen Gal $\alpha 1-3 \mathrm{Gal} \beta 1-(3) 4 \mathrm{GlcNAc}-\mathrm{R}(\alpha-\mathrm{Gal})$ expressed by microbiota bacteria and all mammals, but no by Old World monkeys, apes, and Homo sapiens $(14,15)$. In particular, humans have three frame-shift mutations in the gene (GGTA1) encoding for the enzyme $\alpha 1$,3-galactosyltransferase $(\alpha 1,3 \mathrm{GT})$ that result in premature stop codons truncating the $\alpha 1,3 \mathrm{GT}$ enzyme which prevents the synthesizes of the carbohydrate $\alpha$-Gal (15). Therefore, human cells lost the ability to produce this carbohydrate, which resulted in an almost unique capacity to produce high antibody titers against $\alpha-\mathrm{Gal}(14,15)$. Anti- $\alpha-\mathrm{Gal}$ antibodies (IgM and $\operatorname{IgG})$ induced by gut microbiota inhibited Plasmodium (i.e., $P$. berghei and $P$. yoelii) transmission by Anopheles mosquitoes, with a negative correlation between the levels of anti- $\alpha$-Gal antibodies and the incidence of $P$. falciparum infection in human populations of endemic regions $(7,14)$. Individuals from Mali and Senegal exposed to mosquito bites were not infected by $P$. falciparum when having high anti- $\alpha$-Gal antibody levels $(7,14)$. Strikingly, anti- $\alpha$-Gal humoral response in GGTA1 gene knockout (KO) mice provides "sterilizing immunity" against Plasmodium sporozoites transmission by mosquitoes (14). Sterilizing immunity "is a unique immune status, which prevents effective pathogen infection into the host and is different from the immunity that allows infection but with subsequent successful eradication of the pathogen" (16). Particularly, gut colonization by Escherichia coli O86:B7, which expresses $\alpha$-Gal, blocked Plasmodium infection in $60 \%$ of the mice (14). This was not the case when GGTA1 $\mathrm{KO}$ mice were or were not colonized by E. coli K12 that do not express $\alpha$-Gal (14). Likewise, $\alpha$-Gal immunization, with a TLR9 agonist adjuvant, enhanced the levels of anti- $\alpha$-Gal antibodies and reduced the risk of Plasmodium infection by $88 \%$ compared to $61 \%$ risk reduction without adjuvant (14). Furthermore, $\alpha$-Gal immunization arrested the transit of sporozoites from the skin into the liver, without interfering with sporozoite inoculation by mosquitoes. The cytotoxic effect of anti- $\alpha$-Gal antibodies was restricted to the mice dermis and was dependent on the classical pathway of complement activation (14). It is important to note that the parasitemia, disease severity, and mortality were similar among those GGTA1 KO mice that were infected regardless of gut colonization by E. coli O86:B7 or $\alpha$-Gal immunization. This suggested that $\alpha$-Gal immunity protects against Plasmodium transmission, but not against the erythrocytic stage of this parasite (14). Thus, anti- $\alpha-G a l$ immunity, if effective at the population level, has the potential to influence malaria incidence, but not disease severity or protection once the disease is established.

Likewise, tuberculosis patients in the Iberian Peninsula (Portugal and Spain) had low anti- $\alpha-$ Gal antibody levels when compared to healthy individuals (7). These groundbreaking findings suggested that anti- $\alpha$-Gal antibodies might protect not only against Plasmodium parasites but also against other pathogens expressing $\alpha$-Gal on their surface $(17,18)$. Remarkably, several pathogens such as Plasmodium spp.(14), Mycobacterium marinum (closely related to Mycobacterium ulcerans and Mycobacterium tuberculosis) (7), Leishmania spp. (19), and Trypanosoma spp. $(20,21)$ were reported to produce and express $\alpha$-Gal on their surface, and thus anti- $\alpha$-Gal antibodies could control their infection by complement-mediated lysis (14). The current paradigm is that immunity against $M$. tuberculosis relies exclusively on cellular defense mechanisms (22). However, mounting evidence supports that humoral immunity contributes to protection against tuberculosis $(22,23)$. In agreement with a protective role of antibodies against $M$. tuberculosis, Costello et al. (24) reported that antibody response to the glycolipid lipoarabinomannan limited bacteria dissemination in childhood tuberculosis. And passive immunotherapy using antibodies against different antigens has been shown to be protective in experimental models of tuberculosis (25).

Notably, the structure of blood type B [Gal $\alpha 1-3($ Fuc $\alpha 1,2) \mathrm{Gal}]$ is very similar to antigen $\alpha$-Gal (Figure 1) because they share the disaccharide Gal $\alpha 1-3 \mathrm{Gal}$ (gal2) (8). In addition, gal2 is a crucial and sufficient epitope for anti- $\alpha-G a l$ antibody recognition (26). Accordingly, individuals with blood type $B$ have a reduced antibody response against the related antigens $\alpha$-Gal, gal2, and the blood antigen B (8). This lead us to the hypothesis 
that self-tolerance to blood type B affects the immune response to $\alpha$-Gal, which in turn affects the susceptibility to infectious diseases caused by pathogens carrying $\alpha-\mathrm{Gal}$ on their surface (7). The direct association between blood type B, low anti- $\alpha$-Gal antibody titers, and the susceptibility to pathogens carrying $\alpha$-Gal on their surface remains to be fully verified. However, this hypothesis was partially tested by correlation analysis between the incidence of malaria, tuberculosis, and dengue and the frequency of $\mathrm{ABO}$ blood types in endemic regions (7). The frequency of blood type $\mathrm{B}$ was positively correlated with the incidence of malaria and tuberculosis, but not with the incidence of dengue (7). By contrast, a negative correlation was observed between the frequency of blood type A and the incidence of malaria and tuberculosis (7). Both Plasmodium spp. and Mycobacterium spp. contain $\alpha$-Gal on their surface, while Dengue virus does not produce this antigen $(7,14)$. In agreement with these results, a 4-year prospective cohort study in childhood malaria in Mali showed that children having blood types $\mathrm{B}$ and $\mathrm{AB}$ had higher incidence rate (blood type B: 1.63 and blood type AB: 1.65) compared to those children with blood types A and $\mathrm{O}$ (blood type A: 1.57 and blood type O: 1.45) (11). Other studies in endemic regions supported the association between blood type B and high incidence, prevalence, or severity of malaria $(27,28)$. Similar results were published for tuberculosis (10).

Bhatt et al. (3) reported that malaria control strategies have had a dramatic effect on malaria incidence in sub-Saharan Africa by reducing the incidence of clinical disease by $40 \%$ between 2000 and 2015. Interestingly, we found that the reduction in malaria incidence per country from 2000 to 2015 was negatively correlated with the frequency of blood type B (7). This finding suggests that the control of malaria has been less effective in countries with the highest frequency of blood type B, and therefore more susceptible individuals. Collectively, these results have important implications for the control of infectious microorganisms containing $\alpha$-Gal on their surface.

\section{MICROBIOTA, INFECTIOUS DISEASES, AND ANTI- $\alpha-G A L$ IMMUNITY}

In addition to blood group, gut microbiota composition has also been associated with malaria and tuberculosis. A recent study showed that cecal content transplants from malaria "resistant" or "susceptible" mice to germfree mice resulted in low and high Plasmodium spp. burdens, respectively (29). Further microbiota composition analysis revealed increased abundance of Lactobacillus and Bifidobacterium in resistant mice demonstrating that gut microbiota shaped the severity of malaria (29). In agreement with the protective role of Bifidobacterium against malaria severity, the gut microbiota of Malian children at lower risk of $P$. falciparum infection contained a significantly higher proportion of Bifidobacterium, Streptococcus, and Enterobacteriaceae (i.e., Escherichia and Shigella) compared to subjects at higher risk of $P$. falciparum infection (30). Gut microbiota composition is very different between malaria endemic and non-endemic countries (31). Contrasting microbiota composition can be due to differences in diet (31), but also to host-pathogen adaptations, in which individual from endemic countries acquired, maintain and develop a gut microbiota that may influence protection to malaria transmission and/or tolerance to severe malaria. Interestingly, production of anti- $\alpha-\mathrm{Gal}$ antibodies in humans is thought to be driven by exposure to microbiota bacteria of the Klebsiella spp., Serratia spp., and E. coli spp. expressing $\alpha$-Gal (32). As mentioned above, this has been experimentally tested and gut colonization by the human pathobiont E. coli O86:B7 elicited anti- $\alpha$-Gal antibodies in GGTA1 KO mice and in primates $(33,34)$. We hypothesized that contrasting microbiota composition between malaria endemic and non-endemic countries may have an effect in anti$\alpha$-Gal antibody levels. In fact, anti- $\alpha-$ Gal IgG and IgM antibody levels in healthy individuals from malaria endemic regions are significantly higher than those of individuals from non-endemic regions (Figure 2).

The experiments by Villarino et al. (29) were carried out in wild-type mice that express $\alpha$-Gal and cannot develop anti- $\alpha$ Gal antibodies. Therefore, the protective role of Lactobacillus and Bifidobacterium in these experiments was not related in any way to anti- $\alpha$-Gal immunity. It is remarkable that Malian children microbiota is composed by both Escherichia spp. and Bifidobacterium (30). These two bacteria, when present in the same individual, may decreased simultaneously the risk of malaria infection and disease severity, respectively. Anti- $\alpha-\mathrm{Gal}$ immunity triggered by E. coligut colonization targets Plasmodium sporozoites in the skin immediately after mosquito transmission but once the parasites reach the blood, the anti- $\alpha$-Gal antibodies are not effective (14). Thus, by reaching the blood, the parasites escape the anti- $\alpha$-Gal immunity. In this scenario, the presence of Bifidobacterium in the gut microbiota can play an important role by decreasing malaria severity. Despite results by Villarino et al. (29) were not related to $\alpha$-Gal immunity, the possibility that Lactobacillus and Bifidobacterium influence the response to $\alpha-\mathrm{Gal}$ in humans cannot be rule out.

The role of gut microbiota in tuberculosis remains largely unexplored (35). However, a recent study found that antibioticinduced dysbiosis increased significantly the bacterial burden in

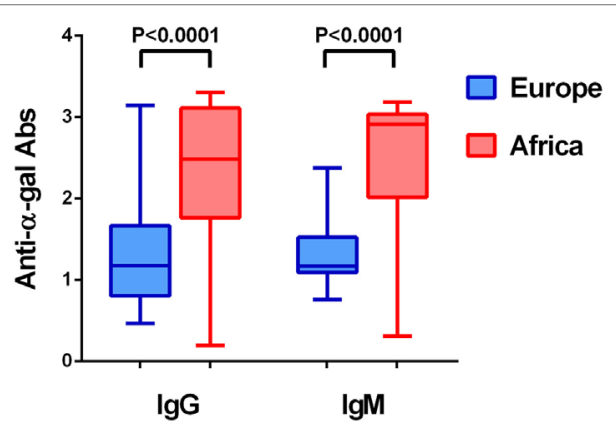

FIGURE 2 | Level of anti- $\alpha$-Gal lgM and IgG antibodies in healthy individuals from Africa and Europe. The figure displays the level of anti- $\alpha-G a l \operatorname{lgM}$ and IgG in individuals from Senegal (Africa) and Portugal and Spain (Iberian Peninsula, Europe). Anti- $\alpha$-Gal IgM and IgG antibody levels (O.D. 450 nm) were determined by ELISA in sera from healthy adults (7). The level of both immunoglobulins was significantly higher in African individuals. 
lungs and dissemination of $M$. tuberculosis to spleen and liver (36). Furthermore, microbiota diversity reconstitution by fecal transplantation significantly reduced the bacterial load in the lungs (36). Further studies should test whether Bifidobacterium and Lactobacillus play a protective role in tuberculosis as in malaria.

\section{CHALLENGES OF DEVELOPING A PROBIOTIC-BASED VACCINE}

The carbohydrate $\alpha$-Gal is a protective antigen $(14,19,37,38)$. $\alpha$-Gal immunization induces an protective immune response against Plasmodium spp. (14)., Trypanosoma cruzi (37), and Leishmania spp. $(19,38)$. This provides the basis to develop a single-antigen pan-vaccine to control major infectious diseases (18). This prospective vaccine can be developed using classical approaches of antigen formulation and immunization by injection. For example, conjugation of $\alpha$-Gal to carrier proteins such as bovine serum albumin (BSA) (14), $\alpha$-Gal-containing neoglycoproteins covalently attached to BSA (38), and virus-like particles displaying the $\alpha$-Gal carbohydrate (19) among others. However, the most innovative implication of the study by Yilmaz et al. (14) is the potential use of probiotic bacteria to elicit protective anti- $\alpha$-Gal antibodies (39). Such approach would have obvious advantages considering that probiotic-based products are safe, easy to distribute, well received by the public, and with a well-established regulatory body (40). Currently, research on the use of probiotics to induce anti- $\alpha$-Gal immunity is very limited. Initial reports showed that consumption of fermented milk containing Lactobacillus case $i$, which express $\alpha$-Gal, in healthy adults did not change anti- $\alpha$-Gal antibody levels (41). However, this preliminary report does not allow concluding that developing an $\alpha$-Gal probiotic-based vaccine is an impossible task. The diversity of best known probiotics Lactobacillus (42), Lactococcus (43), and Bifidobacterium is astonishing (44). For example, the genus Lactobacillus has 154 validly described species and 19 subspecies (42). Exploring such diversity may render promising bacterial species candidates that express $\alpha$-Gal and may also enhance the immunity to this antigen. The GGTA1 KO mice would be a relevant model in these studies. A difficulty may arise when developing a probiotic-based vaccine using Gram-positive bacteria. The $\alpha$-Gal in members of the family Enterobacteriaceae (Gram-negative bacteria, e.g., E. coli spp.) is mainly associated with the bacterial capsule and cell wall glycoproteins, as well as with carbohydrate units of bacterial lipopolysaccharide (LPS) (32). The association of $\alpha$-Gal to highly immunogenic components such as LPS, not present in Gram-positive bacteria, may influence the immune response elicited against this carbohydrate in the intestinal mucosa. Toll-like receptor (TLR) 4 for which
LPS is a specific, and powerful, activator may play a role in the immunity against $\alpha$-Gal associated with LPS. Thus, as previously proposed (39), probiotic-based vaccines using Gram-positive bacteria may be combined with TLR4 agonist. A way to implement this is to transform the candidate Gram-positive bacteria with a plasmid containing LPS specific peptide mimotopes (45). This LPS mimotopes are short peptide sequences of seven amino acids that activate TRL4 signaling pathway and trigger the secretion of inflammatory cytokines by macrophages (45). Grampositive bacteria co-expressing LPS mimotopes and $\alpha$-Gal have the potential to overcome the low antigenicity of $\alpha$-Gal expressed by L. casei (41). Alternatively, probiotic Gram-negative bacteria such as E. coli Nissle 1917 strain (46) can be used. Whether E. coli Nissle 1917 expresses $\alpha$-Gal or not is currently unknown. If these bacteria do not express $\alpha$-Gal naturally, they can be transformed with a plasmid containing bacterial $\alpha$-1,3-galactosyltransferase reported in E. coli (47) and other bacteria (48).

\section{CONCLUDING REMARKS}

The identification of anti- $\alpha-G a l$ immunity as an important factor in malaria transmission (14), together with the finding that blood type B decreases anti- $\alpha-\mathrm{Gal}$ antibody levels increasing the susceptibility to malaria and tuberculosis $(7,8)$, can be used to implement specific measures for disease control. First, blood type B may be considered as a risk factor to develop malaria and tuberculosis. Second, probiotic-based vaccines can be used to induce a protective anti- $\alpha$-Gal immunity in blood type A and $\mathrm{O}$ individuals. This vaccine has the potential to induce a long-lasting protective response against various highly prevalent infectious diseases such as malaria and tuberculosis caused by pathogens with $\alpha$-Gal on their surface. Probiotic-based vaccines could rely on $\alpha$-Gal-producing bacteria such as Lactobacillus spp. transformed with LPS mimotopes to activate TLR4. Alternatively, this vaccine can be based on the probiotic Gramnegative bacteria $E$. coli Nissle 1917 . This probiotic-based vaccine would have low production costs and would be easy to administer to high-risk populations in the poorest regions of the world.

\section{AUTHOR CONTRIBUTIONS}

All authors contributed equally to the realization of the present work.

\section{ACKNOWLEDGMENTS}

We thank members of our laboratories and collaborators for fruitful discussions. We also thank the reviewers for their comments that helped improving an earlier version of this manuscript.

\section{REFERENCES}

1. World Health Organization. Tuberculosis Fact Sheet. (2017). Available from: http://www.who.int/mediacentre/factsheets/fs104/en/

2. World Health Organization. Malaria Fact Sheet. (2017). Available from: http:// www.who.int/mediacentre/factsheets/fs094/en/

3. Bhatt S, Weiss DJ, Cameron E, Bisanzio D, Mappin B, Dalrymple U, et al. The effect of malaria control on Plasmodium falciparum in Africa between 2000 and 2015. Nature (2015) 526:207-11. doi:10.1038/nature15535

4. Ashley EA, Dhorda M, Fairhurst RM, Amaratunga C, Lim P, Suon S, et al. Spread of artemisinin resistance in Plasmodium falciparum malaria. N Engl J Med (2014) 371:411-23. doi:10.1056/NEJMoa1314981 
5. Günther G, Lange C, Alexandru S, Altet N, Avsar K, Bang D, et al. Treatment outcomes in multidrug-resistant tuberculosis. N Engl J Med (2016) 375: 1103-5. doi:10.1056/NEJMc1603274

6. Lynch JB. Multidrug-resistant tuberculosis. Med Clin North Am (2013) 97:553-79. doi:10.1016/j.mcna.2013.03.012

7. Cabezas-Cruz A, Mateos-Hernández L, Alberdi P, Villar M, Riveau G, Hermann E, et al. Effect of blood type on anti- $\alpha$-Gal immunity and the incidence of infectious diseases. Exp Mol Med (2017) 49:e301-8. doi:10.1038/ emm.2016.164

8. Rispens T, Derksen NI, Commins SP, Platts-Mills TA, Aalberse RC. IgE production to $\alpha$-gal is accompanied by elevated levels of specific IgG1 antibodies and low amounts of IgE to blood group B. PLoS One (2013) 8:e55566. doi:10.1371/journal.pone.0055566

9. Cooling L. Blood groups in infection and host susceptibility. Clin Microbiol Rev (2015) 28:801-70. doi:10.1128/CMR.00109-14

10. Rao BN, Reddy VD, Sahu PS, Veerendra Kumar A, david MA, Yugandhar P, et al. The $\mathrm{ABO}$ blood group distribution and pulmonary tuberculosis. J Clin Diagn Res (2012) 6:943-6. doi:10.7860/JCDR.2012.4370.2298

11. Lopera-Mesa TM, Doumbia S, Konaté D, Anderson JM, Doumbouya M, Keita AS, et al. Effect of red blood cell variants on childhood malaria in Mali: a prospective cohort study. Lancet Haematol (2015) 2:e140-9. doi:10.1016/ S2352-3026(15)00043-5

12. Rowe JA, Handel IG, Thera MA, Deans AM, Lyke KE, Koné A, et al. Blood group O protects against severe Plasmodium falciparum malaria through the mechanism of reduced rosetting. Proc Natl Acad Sci U S A (2007) 104:17471-6. doi:10.1073/pnas.0705390104

13. Goel S, Palmkvist M, Moll K, Joannin N, Lara P, Akhouri RR, et al. RIFINs are adhesins implicated in severe Plasmodium falciparum malaria. Nat Med (2015) 21:314-7. doi:10.1038/nm.3812

14. Yilmaz B, Portugal S, Tran TM, Gozzelino R, Ramos S, Gomes J, et al. Gut microbiota elicits a protective immune response against malaria transmission. Cell (2014) 159:1277-89. doi:10.1016/j.cell.2014.10.053

15. Galili U. Significance of the evolutionary $\alpha 1$,3-galactosyltransferase (GGTA1) gene inactivation in preventing extinction of apes and old world monkeys. J Mol Evol (2015) 80:1-9. doi:10.1007/s00239-014-9652-x

16. Dutta A, Huang CT, Lin CY, Chen TC, Lin YC, Chang CS, et al. Sterilizing immunity to influenza virus infection requires local antigen-specific $\mathrm{T}$ cell response in the lungs. Sci Rep (2016) 6:32973. doi:10.1038/srep32973

17. Soares MP, Yilmaz B. Microbiota control of malaria transmission. Trends Parasitol (2016) 32:120-30. doi:10.1016/j.pt.2015.11.004

18. Cabezas-Cruz A, and de la Fuente J. Immunity to $\alpha$-Gal: toward a singleantigen pan-vaccine to control major infectious diseases. ACS Cent Sci (2017) 3(11):1140-2. doi:10.1021/acscentsci.7b00517

19. Moura APV, Santos LCB, Brito CRN, Valencia E, Junqueira C, Filho AAP, et al. Virus-like particle display of the $\alpha$-Gal carbohydrate for vaccination against Leishmania infection. ACS Cent Sci (2017) 3(9):1026-31. doi:10.1021/ acscentsci.7b00311

20. Couto AS, Gonçalves MF, Colli W, de Lederkremer RM. The N-linked carbohydrate chain of the 85-kilodalton glycoprotein from Trypanosoma cruzi trypomastigotes contains sialyl, fucosyl and galactosyl (alpha 1-3)galactose units. Mol Biochem Parasitol (1990) 39:101-7. doi:10.1016/0166-6851(90)90012-B

21. Zamze SE, Ashford DA, Wooten EW, Rademacher TW, Dwek RA. Structural characterization of the asparagine-linked oligosaccharides from Trypanosoma brucei type II and type III variant surface glycoproteins. J Biol Chem (1991) 266:20244-61.

22. Achkar JM, Casadevall A. Antibody-mediated immunity against tuberculosis: implications for vaccine development. Cell Host Microbe (2013) 13:250-62. doi:10.1016/j.chom.2013.02.009

23. Achkar JM, Chan J, Casadevall A. B cells and antibodies in the defense against Mycobacterium tuberculosis infection. Immunol Rev (2015) 264:167-81. doi:10.1111/imr.12276

24. Costello AM, Kumar A, Narayan V, Akbar MS, Ahmed S, Abou-Zeid C, et al. Does antibody to mycobacterial antigens, including lipoarabinomannan, limit dissemination in childhood tuberculosis? Trans R Soc Trop Med Hyg (1992) 86:686-92. doi:10.1016/0035-9203(92)90192-F

25. Balu S, Reljic R, Lewis MJ, Pleass RJ, McIntosh R, van Kooten C, et al. A novel human $\operatorname{IgA}$ monoclonal antibody protects against tuberculosis. J Immunol (2011) 186:3113-9. doi:10.4049/jimmunol.1003189
26. Plum M, Michel Y, Wallach K, Raiber T, Blank S, Bantleon FI, et al. Close-up of the immunogenic a1,3-galactose epitope as defined by a monoclonal chimeric immunoglobulin $\mathrm{E}$ and human serum using saturation transfer difference (STD) NMR. J Biol Chem (2011) 286:43103-11. doi:10.1074/jbc. M111.291823

27. Panda AK, Panda SK, Sahu AN, Tripathy R, Ravindran B, Das BK. Association of $\mathrm{ABO}$ blood group with severe falciparum malaria in adults: case control study and meta-analysis. Malar J (2011) 10:309. doi:10.1186/1475-287510-309

28. Amodu OK, Olaniyan SA, Adeyemo AA, Troye-Blomberg M, Olumese PE, Omotade OO. Association of the sickle cell trait and the ABO blood group with clinical severity of malaria in southwest Nigeria. Acta Trop (2012) 123:72-7. doi:10.1016/j.actatropica.2012.03.013

29. Villarino NF, LeCleir GR, Denny JE, Dearth SP, Harding CL, Sloan SS, et al. Composition of the gut microbiota modulates the severity of malaria. Proc Natl Acad Sci U S A (2016) 113:2235-40. doi:10.1073/pnas.1504887113

30. Yooseph S, Kirkness EF, Tran TM, Harkins DM, Jones MB, Torralba MG, et al. Stool microbiota composition is associated with the prospective risk of Plasmodium falciparum infection. BMC Genomics (2015) 16:631. doi:10.1186/ s12864-015-1819-3

31. Aakko J, Endo A, Mangani C, Maleta K, Ashorn P, Isolauri E, et al. Distinctive intestinal Lactobacillus communities in 6-month-old infants from rural Malawi and Southwestern Finland. J Pediatr Gastroenterol Nutr (2015) 61:641-8. doi:10.1097/MPG.0000000000000878

32. Galili U, Mandrell RE, Hamadeh RM, Shohet SB, Griffiss JM. Interaction between human natural anti-alpha-galactosyl immunoglobulin $\mathrm{G}$ and bacteria of the human flora. Infect Immun (1988) 56:1730-7.

33. Mañez R, Blanco FJ, Díaz I, Centeno A, Lopez-Pelaez E, Hermida M, et al. Removal of bowel aerobic gram-negative bacteria is more effective than immunosuppression with cyclophosphamide and steroids to decrease natural alpha-galactosyl IgG antibodies. Xenotransplantation (2001) 8(1):15-23.

34. Posekany KJ, Pittman HK, Bradfield JF, Haisch CE, Verbanac KM. Induction of cytolytic anti-Gal antibodies in alpha-1,3-galactosyltransferase gene knockout mice by oral inoculation with Escherichia coli O86:B7 bacteria. Infect Immun (2002) 70(11):6215-22.

35. Denny JE, Powell WL, Schmidt NW. Local and long-distance calling: conversations between the gut microbiota and intra- and extra-gastrointestinal tract infections. Front Cell Infect Microbiol (2016) 6:41. doi:10.3389/ fcimb.2016.00041

36. Khan N, Vidyarthi A, Nadeem S, Negi S, Nair G, Agrewala JN. Alteration in the gut microbiota provokes susceptibility to tuberculosis. Front Immunol (2016) 7:529. doi:10.3389/fimmu.2016.00529

37. Almeida IC, Milani SR, Gorin PA, Travassos LR. Complement-mediated lysis of Trypanosoma cruzi trypomastigotes by human anti-alpha-galactosyl antibodies. J Immunol (1991) 146:2394-400.

38. Iniguez E, Schocker NS, Subramaniam K, Portillo S, Montoya AL, Al-Salem WS, et al. An $\alpha$-Gal-containing neoglycoprotein-based vaccine partially protects against murine cutaneous leishmaniasis caused by Leishmania major. PLoS Negl Trop Dis (2017) 11:e0006039. doi:10.1371/journal.pntd.0006039

39. Cabezas-Cruz A, Valdés JJ, de la Fuente J. Control of vector-borne infectious diseases by human immunity against $\alpha$-Gal. Expert Rev Vaccines (2016) 15:953-5. doi:10.1080/14760584.2016.1181547

40. Kumar H, Salminen S, Verhagen H, Rowland I, Heimbach J, Bañares S, et al. Novel probiotics and prebiotics: road to the market. Curr Opin Biotechnol (2015) 32:99-103. doi:10.1016/j.copbio.2014.11.021

41. Mangold A, Hercher D, Hlavin G, Liepert J, Zimmermann M, Kollmann D, et al. Anti-alpha-Gal antibody titres remain unaffected by the consumption of fermented milk containing Lactobacillus case i in healthy adults. Int J Food Sci Nutr (2012) 63:278-82. doi:10.3109/09637486.2011.622741

42. Mikelsaar M, Sepp E, Štšepetova J, Songisepp E, Mändar R. Biodiversity of intestinal lactic acid bacteria in the healthy population. Adv Exp Med Biol (2016) 932:1-64. doi:10.1007/5584_2016_3

43. van Hylckama Vlieg JE, Rademaker JL, Bachmann H, Molenaar D, Kelly WJ, Siezen RJ. Natural diversity and adaptive responses of Lactococcus lactis. Curr Opin Biotechnol (2006) 17:183-90. doi:10.1016/j.copbio.2006.02.007

44. Bottacini F, Ventura M, van Sinderen D, O'Connell Motherway M. Diversity, ecology and intestinal function of bifidobacteria. Microb Cell Fact (2014) 13(Suppl 1):S4. doi:10.1186/1475-2859-13-S1-S4 
45. Shanmugam A, Rajoria S, George AL, Mittelman A, Suriano R, Tiwari RK. Synthetic toll like receptor-4 (TLR-4) agonist peptides as a novel class of adjuvants. PLoS One (2012) 7:e30839. doi:10.1371/journal.pone.0030839

46. Scaldaferri F, Gerardi V, Mangiola F, Lopetuso LR, Pizzoferrato M, Petito V, et al. Role and mechanisms of action of Escherichia coli Nissle 1917 in the maintenance of remission in ulcerative colitis patients: an update. World J Gastroenterol (2016) 22:5505-11. doi:10.3748/wjg.v22.i24.5505

47. Chen C, Liu B, Xu Y, Utkina N, Zhou D, Danilov L, et al. Biochemical characterization of the novel $\alpha$-1,3-galactosyltransferase WclR from Escherichia coli O3. Carbohydr Res (2016) 430:36-43. doi:10.1016/j.carres. 2016.04.012

48. Han W, Cai L, Wu B, Li L, Xiao Z, Cheng J, et al. The wciN gene encodes an $\alpha$-1,3-galactosyltransferase involved in the biosynthesis of the capsule repeating unit of Streptococcus pneumoniae serotype 6B. Biochemistry (2012) 51:5804-10. doi:10.1021/bi300640b

Conflict of Interest Statement: The research was conducted in the absence of any commercial or financial relationships that could be construed as a potential conflict of interest.

Copyright (c) 2017 Cabezas-Cruz and de la Fuente. This is an open-access article distributed under the terms of the Creative Commons Attribution License (CC BY). The use, distribution or reproduction in other forums is permitted, provided the original author(s) or licensor are credited and that the original publication in this journal is cited, in accordance with accepted academic practice. No use, distribution or reproduction is permitted which does not comply with these terms. 